ISSN 00156043

NOTAS

\title{
I 5-M. Apuntes para el análisis de un movimiento en construcción
}

\author{
Jesús Sanz' y Óscar Mateos²
}

Resumen: El movimiento 15-M está suponiendo una importante novedad en el panorama político y social. Este artículo tiene como objetivo aproximarse a su origen, así como a algunas de sus principales características. Asimismo, se analizan los factores contextuales que explican su emergencia y se hace un acercamiento a las principales novedades que este movimiento entraña en términos de transformaciones políticas y de acción colectiva. Se destacan también cuestiones tales como el repertorio de formas de movilización empleadas, el papel que ha jugado Internet en la amplificación de la protesta, las formas de organización surgidas en torno al movimiento, el lenguaje empleado o sus formas de deliberación y de construcción de sus propuestas de acción. Finalmente, el artículo termina con una reflexión sobre los escenarios de futuro existentes sobre dicho movimiento.

Palabras clave: 15-M, acción colectiva, crisis, formas de movilización, movimientos sociales, Spanish Revolution.

Fecha de recepción: II de octubre de 201 I.

Fecha de aceptación definitiva: 20 de octubre de $201 \mathrm{I}$.

\footnotetext{
1 Universidad Complutense de Madrid. Centro de Estudios Cristianisme i Justícia, Barcelona.

${ }^{2}$ Universidad Ramon Llull de Barcelona. Responsable del área social del Centro de Estudios Cristianisme i Justícia, Barcelona.
} 


\section{5-M. Notes for the analysis of a movement that is under way}

The 15-M movement is becoming an important novelty in the political and social landscape. This article aims to approach its origin as well as some of its main features. It also analyses the contextual factors that explain its emergence and is an approach to the major developments involved in this movement in terms of political change and collective action. Also highlighted are such issues as the range of types of mobilisation used, the role played by Internet in the amplification of the protest, the types of organization emerging around the movement, the language used and the forms of deliberation, and how their proposals for action are constructed. Finally, the article concludes with a reflection on future scenarios for this movement.

Key words: I5-M, collective action, crisis, types of mobilization, social movements, Spanish Revolution

\section{Mouvement 15-M. Notes pour I'analyse d'un mouvement en construction}

Le mouvement $15-M$ représente une importante nouveauté dans le panorama politique et social. L'objectif de cet article est de se rapprocher de son origine ainsi qu'à certaines de ses principales caractéristiques. De même, les auteurs analysent les facteurs contextuels qui expliquent l'urgence de ce mouvement ef l'approche aux principales nouveautés que ce mouvement implique en termes de transformation politique etd'action collective. Ils mettent également en avant des questions telles le répertoire des formes de mobilisations employées, le rôle qu'a joué Internet dans l'étendue des protestations, les formes d'organisations apparues autour du mouvement, le langage employé ou ses formes de délibération et de constructions de ses proposition d'action. Finalement, l'article conclut avec une réflexion sur les scénarios d'avenir existants autour de ce mouvement.

Mots-clé: 15-M, Action collective, crise, formes de mobilisation, mouvements sociaux, Spanish Revolution.

\section{Introducción}

En pocas semanas, el movimiento $15-M$ ha reconfigurado el paisaje político y social de todo un país. Pero, ìnadie presagiaba la \#spanishrevolution, tal y como rezaba uno de los carteles expuesto en alguna de las plazas? ¿Nadie había intuido las posibles reacciones y consecuencias de un contexto socioeconómico y sociopolítico que se ha ido degradando y que había avocado a casi la mitad de nuestros jóvenes al paro? ¿2Nadie se imaginó las plazas de nuestras ciudades llenas a rebosar de gente, de carteles, de ideas, de creatividad, de rabia, de sue- 
ños de futuro? ¿2Nadie adivinó la posibilidad de que miles de tuits pudieran hacer tambalear las declaraciones de partidos políticos, especialmente de izquierdas, de sindicatos, de los principales medios de comunicación? ¿Nadie? La respuesta es sí, nadie. Ni tan siquiera en el más imaginativo de los sueños alguien podría haber profetizado el fondo, la forma, el alcance y el horizonte -todavía incierto- de todo un movimiento que tan sólo está dando sus primeros pasos.

En las siguientes páginas trataremos de aproximarnos a diferentes aspectos de dicho movimiento como su origen; algunas de sus características; las principales novedades que entraña en el marco de la acción colectiva; y los posibles escenarios de futuro que existen sobre el mismo.

\section{Análisis cronológico del origen y evolución del movimiento I5-M: Una manifestación de mayo}

En la evolución del movimiento 15-M se pueden diferenciar tres etapas: una primera que va desde su aparición hasta la jornada electoral del 22 de mayo; una segunda que comprende desde esta última fecha hasta la convocatoria de la protesta del 19 de junio, y una última que analiza la evolución desde esta manifestación hasta nuestros días. El análisis detallado de esta cronología es importante para observar los rasgos más característicos del movimiento que luego estudiaremos.

\section{I. Del I5-M al 22-M: emergencia y efervescencia del movimiento}

Domingo, 15 de Mayo de 201 1, 18:00 de la tarde. Decenas de miles de personas se manifiestan en Madrid y en más de 50 ciudades españolas convocados por la Plataforma Democracia Real Ya y por otras entidades y personas adheridas a esta convocatoria bajo el lema "No somos mercancías en manos de políticos y banqueros". Esta plataforma se presentaba de la siguiente manera:

(...) nosotros los desempleados, los mal remunerados, los subcontratados, los precarios, los jóvenes... queremos un cambio y un futuro digno. Estamos hartos de reformas antisociales, de que nos dejen en el paro, de que los bancos que han provocado la crisis nos suban las hipotecas o se queden con nuestras viviendas, de que nos impongan leyes que limitan nuestra libertad en beneficio de los poderosos. Acusamos a los poderes políticos y económicos de nuestra precaria situación y exigimos un cambio de rumbo.

En los carteles de la manifestación se invitaba a "tomar la calle" y se animaba a la gente a ir sin símbolos de carácter político o sindical que fueran representativos. El manifiesto exigía un cambio en el orden de prioridades, se reafirmaba la exis- 
tencia de derechos básicos (vivienda, trabajo, salud o educación) que debían ser cubiertos y se reclamaba una revolución ética que pusiese el dinero al servicio del ser humano. En las propuestas de esta plataforma se planteaban aspectos como la eliminación de los privilegios de la clase política, la lucha contra el desempleo, la apuesta por unos servicios públicos de calidad, un mayor control de las entidades bancarias o una fiscalidad progresiva. La respuesta a esta convocatoria, que venía gestándose desde hacía meses en las redes sociales, sorprendió a los organizadores, convirtiéndose en uno de los mayores éxitos de movilización ciudadana ajena a partidos políticos y sindicatos. Al mismo tiempo, esta manifestación vino a irrumpir en el ecuador de la campaña electoral de las elecciones municipales y autonómicas del 22 de mayo.

Sin embargo, lo más sorprendente estaba por llegar. Tras la manifestación, un centenar de jóvenes decidieron acampar en la Puerta del Sol de Madrid con la intención de continuar la protesta y de permanecer en la plaza hasta el domingo 22 , fecha de los comicios. Una vez adoptada esta decisión y utilizando "Twitter" (donde nace \#acampadasol) se convoca a la concentración, reuniéndose el lunes 16 por la tarde unos centenares de personas. Allí, en asamblea ciudadana, se decide continuar la acampada. La convocatoria queda desbordada por los acontecimientos y por la espontaneidad de esta nueva iniciativa. Mientras tanto, en los medios de comunicación surge el desconcierto y los interrogantes para saber quiénes son aquellas personas que han iniciado la acampada, a los que se etiqueta de "antisistema". Esa misma noche, en torno a las 5 de la mañana la policía desaloja a los cerca de 200 acampados que se encontraban en la Puerta del Sol. Las imágenes del desalojo, que mostraban la resistencia no violenta utilizada así como los llamamientos a la continuación de la acampada, comienzan a circular en las redes sociales.

En la tarde del día 17, ante la sorpresa general, miles de personas llenan la Puerta del Sol rechazando el desalojo policial $y$, tras constituirse en asamblea, deciden iniciar una nueva acampada. El ejemplo de la acampada de Sol empieza a proliferar por diversas ciudades hasta alcanzar el centenar de acampadas en el conjunto del Estado e incluso en Europa. Mientras, en la red los "hashtags" van cambiando y multiplicándo con ello el efecto viral: \#acampadasol, \#acampadabcn, \#spanishrevolution, \#tomalaplaza, \#globalcamp, \#movimiento15-M...

Durante los siguientes días, a pesar de las prohibiciones de la Junta Electoral Central, las distintas acampadas irán desarrollando una misma dinámica. En la acampada de la Puerta del Sol, por ejemplo, se habilitarán espacios específicos en diferentes zonas: reparto de comida, servicios, enfermería repleta de medicamentos donados, biblioteca, zona infantil, baños, placas solares o zonas habilitadas para el descanso. A su vez, se irán ampliando el número de comisiones, mientras los 
voluntarios siguen aumentando (llega a haber más de cien abogados apuntados en la Comisión de legal). Por otro lado, los grupos de trabajo diversifican sus ejes de reflexión, a la vez que algunos grupos ya existentes se dividirán en subgrupos donde se abordan aspectos más concretos (por ejemplo, dentro del grupo de economía se crean subgrupos de empleo, empresa, países empobrecidos o sistemas financieros internacionales).

Hay que decir que las acampadas se caracterizarán por su carácter interclasista y por la confluencia en ellas de miembros de los movimientos sociales críticos y con una larga experiencia militante, con otros jóvenes indignados para los cuales su adhesión en el movimiento supone su primera experiencia de activismo político y una forma de expresar el malestar social. En el caso de muchos de estos últimos, ahora sí se sentirán llamados a participar en esta movilización, en abierto contraste con el rechazo o indiferencia que habían suscitado otros llamamientos a la protesta que actores políticos tradicionales como sindicatos o partidos políticos habían realizado previamente ${ }^{3}$.

Por otra parte, los días previos a la celebración de las elecciones, se suceden los actos pacíficos de protesta ante la prohibición de concentrarse realizada por la Junta Electoral. Miles de personas en todas las plazas convocan caceroladas y continúan celebrando las cada vez más multitudinarias asambleas. Al mismo tiempo, los medios de comunicación empiezan a preguntarse sobre el posicionamiento político de las acampadas ante los comicios inminentes (¿alentarán el voto nulo o la abstención? ¿se decantarán por los partidos minoritarios?). En respuesta, y ante los comentarios y titulares en ocasiones tendenciosos, las acampadas aprobarán algunos comunicados, reafirmándose como un movimiento apartidista y cuyo objetivo es ir mucho más allá de las elecciones.

El 22 de mayo, el Partido Popular (PP) resulta claro vencedor de las elecciones, el Partido Socialista (PSOE) se desploma (especialmente en sus tradicionales feudos electorales), a la vez que se produce un tímido avance de Izquierda Unida (IU) y de UPyD. Aunque el voto nulo y el voto a partidos minoritarios aumentarán de forma notable (sobre todo en Barcelona), no se producirán cambios significativos en el panorama electoral. Ese mismo día por la tarde, las diferentes asambleas decidirán continuar al menos hasta el 29 de mayo.

\footnotetext{
${ }^{3}$ En este sentido, cabe recordar por ejemplo la menor movilización suscitada con motivo del día 1 de mayo celebrado dos semanas antes, o la tibia respuesta que tuvieron otras movilizaciones convocadas anteriormente.
} 


\subsection{Del 22-M al 19-J: Descentralización y metamorfosis}

Una de las primeras decisiones adoptadas en las diferentes asambleas tras la jornada electoral fue la idea de descentralizar el movimiento a los barrios y pueblos e ir constituyendo allí nuevas asambleas vecinales. Al mismo tiempo, la actividad y el trabajo de las diferentes comisiones continuó, si bien con menos gente que en los días anteriores. En Sol, algunos comerciantes cercanos al lugar de la acampada empezaron a denunciar pérdidas en sus negocios, a la vez que desde algunos medios de comunicación se instaba a efectuar un desalojo policial, animando a cumplir la legalidad vigente. No obstante, la legitimidad social que va adquiriendo el 15-M es extraordinaria. Según diferentes encuestas realizadas en aquellos días, más del $70 \%$ de la población encuestada declara simpatizar con el espíritu y los objetivos del movimiento ${ }^{4}$.

La carga policial efectuada en la acampada de Barcelona en la mañana del 27 de mayo será otro de los acontecimientos que marquen la trayectoria inicial del 15-M. Las imágenes de la actuación policial circularán rápidamente por las diferentes redes sociales y desembocarán en la petición de dimisión del Conseller de Interior del Gobierno catalán, Felip Puig y en una protesta multitudinaria.

Mientras tanto, el movimiento dará un paso determinante en su proceso de descentralización. Al igual que sucede en diferentes lugares del territorio, el 29 de mayo 250 barrios y municipios de Madrid organizan sus propias asambleas llamando a los vecinos de la zona a participar en ellas y a apoyar el movimiento, en general, con buen éxito de participación. Cada una de estas asambleas trabajará de forma autónoma en sus propuestas y en las acciones que se realizarán, mientras se trabaja en diferentes mecanismos de coordinación entre estas asambleas y la asamblea de Sol con el fin de intentar dotar al movimiento de un mecanismo ágil y descentralizado en la toma de decisiones. Los días 5 y 6 de junio, personas procedentes de diferentes acampadas, se reúnen para coordinar las acciones de protesta del movimiento y convocan una manifestación general para el 19 de junio en contra del Pacto del euro. Asimismo, tras varios días de deliberaciones, el 12 de junio se decide levantar el campamento de Sol y dejar allí un puesto que haga las veces de punto de información sobre el movimiento. No obstante, serán las acampadas de cada ciudad las que decidirán de forma autónoma si continuar o no.

Las acciones previas al 19 de junio se suceden con una concentración frente al Congreso de los Diputados para protestar contra la reforma laboral o diferentes

${ }^{3}$ Centro de lnvestigaciones Sociológicas (CIS), "Avance de resultados del estudio 2909 Barómetro de julio de 2011 ". En: http://www.cis.es/cis/opencms/ES/NoticiasNovedades/Documentacion 2909.html. 
concentraciones frente a los ayuntamientos en su constitución el día 11. El 14 de junio, unas dos mil personas se concentran frente al Parlament de Catalunya, coincidiendo con la votación de los nuevos presupuestos de la Generalitat, para protestar por los recortes sociales. La multitud rodea el edificio impidiendo la entrada a algunos diputados y se producen algunos incidentes provocados por una minoría de los congregados. Estos incidentes suscitarán la condena de los partidos políticos, mientras que el $15-M$ emitirá un comunicado en el que se desvinculará de los actos violentos acaecidos. En los días sucesivos, se sucederán los editoriales y los debates en diferentes medios de comunicación en los que se cuestiona el carácter pacífico del movimiento y su estrategia no violenta.

Con el debate de fondo abierto, la manifestación del día 19 de junio es un éxito. La protesta más masiva tiene lugar en Barcelona con la presencia de más de 100.000 personas. En Madrid, seis marchas parten desde diferentes puntos de la ciudad a las que progresivamente se van uniendo las asambleas de barrio. En el resto de las ciudades, las manifestaciones resultarán un éxito de participación y ausencia de incidentes lo que se interpreta como un claro indicio de la buena salud del movimiento y su aceptación entre la ciudadanía. Al día siguiente, diferentes marchas a pie comenzarán a salir desde diferentes puntos de España con la intención de confluir en el mes de julio en Madrid y dar continuidad a las protestas. A partir de entonces, el movimiento pasará a incorporar nuevas acciones a su repertorio, tales como la paralización de desahucios hipotecarios o de protesta contra el cierre de centros de salud. Todo ello en un contexto en el que las asambleas vecinales van centrándose en la realización de acciones concretas en el ámbito local.

\subsection{Del I9-J hasta la actualidad: ¿hacia una cierta internacionalización?}

Sábado 23 de julio por la tarde. Las seis marchas que semanas atrás habían salido de diferentes puntos hacen su entrada en Madrid. A su paso por localidades de diferente tamaño, han ido aglutinando cada vez a más gente. Todas las marchas acaban confluyendo en la Puerta del Sol donde celebran una asamblea. El domingo 24, en plenas vacaciones de verano y en medio de un puente festivo, más de 35.000 personas marchan por la tarde desde Atocha hasta la Puerta del Sol bajo el lema: "No es crisis: es el sistema".

Al día siguiente, tiene lugar el I Foro Social 15-M con la celebración de diferentes espacios de debate. En el foro de Economía, Joseph Stiglitz, Premio Nobel de Economía que se encontraba participando en un curso de verano en Madrid, realiza una pequeña intervención en la que expresa su apoyo al movimiento. Entre las acciones de futuro, se habla de la realización de una marcha a Bruselas 
que prevé su llegada a esta ciudad para el 8 de octubre y la celebración de una manifestación internacional el 15 de octubre.

En este proceso, el movimiento también ha logrado un cierto impacto a escala internacional. En los siguientes meses a su inicio, numerosas ciudades europeas han intentado emular el 15-M como forma de movilización. Dentro de estas ciudades, destacaron las manifestaciones masivas surgidas en Atenas. También en EEUU, la iniciativa \#takewallstreet, en la que se ha denunciado las responsabilidades y la impunidad del mundo financiero en la actual crisis, se ha caracterizado por replicar algunas de las formas de movilización utilizadas en España. Todo ello hace pensar que estamos ante un movimiento todavía muy joven pero de largo recorrido, que ha sabido utilizar nuevos lenguajes y herramientas y catalizar el descontento social en una coyuntura de crisis sistémica. Los siguientes apartados tienen como objetivo adentrarse en los motivos de fondo que explican el surgimiento del 15-M, así como las novedades que el movimiento ha supuesto desde el punto de vista de la acción colectiva.

\section{CUADRO I. Cronología del movimiento I5-M (mayo-octubre 20 I I)}

\begin{tabular}{|c|c|}
\hline 15 de mayo & $\begin{array}{l}\text { - Manifestación convocada por la Plataforma Democracia Real Ya bajo el } \\
\text { lema "No somos mercancías en manos de políticos y banqueros" en más } \\
\text { de } 50 \text { ciudades. } \\
\text { - Algunas personas deciden acampar en la Puerta de Sol de Madrid. }\end{array}$ \\
\hline 16 de mayo & $\begin{array}{l}\text { - Desalojo de las personas que habían acampado, difundido en las redes } \\
\text { sociales. }\end{array}$ \\
\hline 17 de mayo & $\begin{array}{l}\text { - Miles de personas protestan contra el desalojo y se aprueba por asamblea } \\
\text { una nueva acampada. }\end{array}$ \\
\hline $\begin{array}{l}17-22 \text { de } \\
\text { mayo }\end{array}$ & $\begin{array}{l}\text { - Las acampadas proliferan en varias ciudades españolas, que van con- } \\
\text { gregando a miles de personas y desarrollando comisiones y grupos de } \\
\text { trabajo y de organización. }\end{array}$ \\
\hline $22 \mathrm{~d}$ & $\begin{array}{l}\text { - Elecciones municipalesy autonómicas que } \\
\text { continuar e ir descentralizando el movin }\end{array}$ \\
\hline 27 de mayo & - Carga policial en la acampada de Barcelona. \\
\hline 29 de mayo & drid organizan sus propias asambleas. \\
\hline 5-6 de junio & $\begin{array}{l}\text { - Encuentro inter-acampadas en el que se consensuan nuevas protestas y } \\
\text { acciones. }\end{array}$ \\
\hline $12 c$ & $\begin{array}{l}\text { - La asamblea en Sol decide levantar el campamento, dejando un punto de } \\
\text { información. Algunas acampadas en el resto de ciudades ya habían sido } \\
\text { levantadas, otras deciden continuar. }\end{array}$ \\
\hline
\end{tabular}




\begin{tabular}{|l|l|}
\hline 14 de junio & $\begin{array}{l}\text { - Concentración frente al Parlament de Catalunya, que acaba con incidentes } \\
\text { y polémica. }\end{array}$ \\
\hline 19 de junio & $\begin{array}{l}\text { - Manifestaciones masivas convocadas por el 15-M contra el Pacto del } \\
\text { Euro. }\end{array}$ \\
\hline $\mathbf{2 3}$ de julio & - Llegada a Madrid de las diferentes marchas ciudadanas. \\
\hline $\mathbf{2 4}$ de julio & - Manifestación en Madrid con más de 35.000 personas. \\
\hline $\mathbf{2 5}$ de julio & $\begin{array}{l}\text { - I Foro Social 15-M, con la participación espontánea del Premio Nobel de } \\
\text { Economía, Joseph Stiglitz. }\end{array}$ \\
\hline Julio-Agosto & $\begin{array}{l}\text { - Se producen algunas protestas en varias ciudades europeas. Manifesta- } \\
\text { ciones masivas en Tel Aviv. }\end{array}$ \\
\hline Septiembre & - Tiene lugar la iniciativa \#takewallstreet en EEUU. \\
\hline $\mathbf{8 ~ d e ~ o c t u b r e ~}$ & - Marcha a Bruselas \\
\hline 15 de octubre & - Manifestación convocada a nivel internacional. \\
\hline
\end{tabular}

Elaboración propia.

\section{Factores contextuales que explican la aparición del movi- miento I5-M}

¿Qué factores explican la emergencia del movimiento 15-M? ¿Qué elementos ayudan a entender su impacto y legitimidad social y el gran alcance que sus convocatorias, protestas e iniciativas de todo tipo han tenido en esta primera fase del movimiento? A continuación nos centraremos en tres aspectos fundamentales: el contexto sociopolítico y socioeconómico en el que surge el movimiento; la progresiva consolidación de una "metanarrativa" de la indignación como posible elemento catalizador de la desafección y el malestar social, y la existencia de algunas experiencias previas, muchas de ellas vehiculadas a través de internet, que podrían explicar algunas de las nuevas formas planteadas por el 15-M.

\section{I. Polarización socioeconómica y desafección política como contexto}

Para entender el contexto en el que las movilizaciones han ido fraguándose en los últimos años hay que aludir, en primer lugar, al proceso de polarización socioeconómica cada vez más evidente para el conjunto de la ciudadanía que ha ido generando importantes agravios. 
Por una parte, España alberga el segundo mayor índice de desigualdad económica en la UE-15, sólo detrás de Portugal ${ }^{5}$. Un $63 \%$ de españoles viven con mil euros o menos al mes ${ }^{6}$, la tasa de pobreza relativa afecta a una de cada cinco personas ${ }^{7}$, a la vez que en el último año más de 250.000 familias han sido desahuciadas por no pagar la hipoteca ${ }^{8}$ y la mayoría de nuestros pensionistas (el $77 \%$ ) no llega a los mil euros (con un gasto en pensiones dos puntos por debajo de la media europea) ${ }^{9}$. A su vez, el paro juvenil entre menores de 24 años (como también en términos generales, con el $21 \%$ de desempleo), alcanza ya casi a la mitad de nuestros jóvenes, en la generación considerada como "la mejor preparada de la historia de España"10. Finalmente, casi un millón y medio de hogares en España tienen a todos sus miembros en paro.

En contraposición a estos datos, nos encontramos otro país muy diferente, caracterizado por una presión fiscal en el que los tipos impositivos sobre las rentas altas han caído diez puntos porcentuales desde 1993 y sólo un punto para las llamadas clases medias (situando el total de nuestra presión fiscal diez puntos por debajo de la media europea) ${ }^{11}$. Un país donde el fraude fiscal (correspondiendo el 73\% a las grandes fortunas) también está muy por encima de los parámetros europeos ${ }^{12}$; y en el que se encuentran los directivos mejor pagados de toda Europa (los 584 consejeros y altos directivos de las empresas del IBEX 35 cobraron un millón de

${ }^{4}$ Según el Instituto Valenciano de Investigación Económica (IVIE), en 2007, el 10\% más rico de los españoles concentraba una renta 7,6 veces superior a la del $10 \%$ más pobre, en: http://www.ivie.es/ downloads/docs/ch/ch117.pdf

5 "El 63\% de los trabajadores en España es mileurista", Público, 25 de agosto de 2009, en: http:// www.publico.es/dinero/246194/el-63-de-los-trabajadores-en-espana-es-mileurista

${ }^{6}$ Instituto Nacional de Estadística (INE).

7 "Los desahucios amargan a 200.000 familias", en Público: http://www.publico.es/dinero/341928/ los-desahucios-amargan-a-200-000-familias

8 "El 77\% de los pensionistas no llega a mil euros", en El Mundo, en: http://mundo-edicion-impresa. vlex.es/vid/pensionistas-no-llega-mil-euros-218075405

9 "El récord del paro juvenil amenaza con crear 'una generación perdida"", El Mundo, en: hittp:// www.elmundo.es/mundodinero/2010/08/11/economia/1281540134.html

10 "Aparcar las diferencias para ganar la calle", Diagonal Periódico, en: http://www. diagonalperiodico. net/Aparcar-las-diferencias-para-ganar.html

${ }^{11}$ Sindicato de técnicos del Ministerio de Hacienda (Gestha), en: http://www.gestha.es/ 
euros de media, un sueldo equivalente a 113 salarios mínimos españoles $)^{13}$. $O$ donde muchas de las grandes empresas han obtenido beneficios records (como es el caso de Telefónica) a la vez que aprobaban despidos masivos ${ }^{14}$. Asimismo, la ciudadanía española ha visto en los últimos años cómo el salario medio ha tendido a la moderación e incluso a la reducción en la etapa de crecimiento económico (con una disminución del poder adquisitivo del 4\% entre 1995 y 2005, según la OCDE), mientras los beneficios empresariales crecían un $73 \%$ en esos años en medio de llamadas a la austeridad y la contención salarial ${ }^{15}$.

Este proceso de dualización social, que ya había sido advertido por varias instituciones e informes antes incluso del estallido de la crisis, ha sido una gran fuente de desafección y de indignación a la que cabe sumar en la última etapa el anuncio de rescates bancarios (100.000 millones de euros destinados a salvar el colapso del sistema financiero), en contraposición a los grandes recortes sociales que se han presentado como "inevitables".

El descontento motivado por la creciente polarización social también se ha centrado, en segundo lugar, en la calidad democrática y en la crisis de la representatividad política. Las decisiones económicas tomadas desde mayo de 2010 por el Gobierno español bajo la presión de los "mercados" han visibilizado con más fuerza algunos déficits de la "democracia de baja intensidad", utilizando la expresión acuñada por de SousA SANTOS (2005). Así, a algunas cuestiones ya presentes como la existencia de una Constitución que da síntomas de agotamiento en bastantes aspectos (en el incumplimiento de los artículos de contenido más social, por ejemplo), se ha sumado la ausencia o escasez de instrumentos de participación y consulta hacia la ciudadanía, el gradual proceso de distanciamiento de la población con las instituciones políticas tradicionales (las "peor valoradas", según los diversos sondeos del CIS desde hace varios años) o el escaso margen de los estados para decidir su política económica en el contexto de globalización y de pertenencia a la zona euro.

12 "Sueldos records en plena crisis", El País, en: hitp://www.elpais.com/articulo/economia/Sueldos/ record/plena/crisis/elpepueco/20100516elpepieco 1/Tes

13 "Telefónica supera los 10.000 millones de beneficio por las plusvalías en Vivo", en El País, 26 de febrero de 2011 , en: http://www.elpais.com/articulo/economia/Telefonica/supera/10000/millones/ beneficio/plusvalias/Vivo/elpepieco/20110226elpepieco_7/Tes?print=1

${ }^{14}$ Ambos datos en: "El salario real medio ha bajado un $4 \%$ en 10 años pese al fuerte crecimiento económico", El País, 24 de junio de 2007, en: http://www.elpais.com/articulo/economia/salario/real/medio/ ha/bajado/anos/pese/fuerte/crecimiento/economico/elpepueco/20070624elpepieco 1/Tes 
Algunas de estas dinámicas han quedado reflejadas en los diferentes lemas utilizados en las acampadas y protestas, tales como "Error en el sistema. Democracia not found", o de forma más poética con la irónica recreación del verso de Pablo Neruda "Me gustas democracia pero estás como ausente". Junto a estos elementos, hay un componente de desafección más profundo que hay que señalar y que se expresa, por ejemplo, con el grito de "lo llaman democracia y no lo es". Este grito, muy presente en las manifestaciones, simboliza el cuestionamiento hecho por el movimiento sobre los consensos generados durante los años de democracia en torno a la denominada por Guillem MARTíNEZ "cultura de la transición", una cultura caracterizada por prescribir ya de entrada los límites de lo posible: la representación política y el mercado como único marco concebible, practicable y deseable para la vida en común ${ }^{16}$. Si atendemos a que un grito así era impensable en cualquier manifestación hace 15 ○ 20 años en España, país donde tras la transición democrática, el recuerdo de la guerra civil y la dictadura estaban muy presentes, podemos afirmar que este lema indica cierta fractura generacional.

La crisis de la representatividad en la toma de decisiones ha quedado plasmada en el grito de "no nos representan", muy presente en todas las concentraciones. Así, con este grito se denuncia la reducción de la vida democrática a la mera participación electoral sin otras vías de participación, lo que hace que la emisión del voto se convierta en poco menos que un "cheque en blanco" para tomar todo tipo de decisiones en los siguientes cuatro años por parte de los elegidos. A estos elementos, además, hay que añadir la existencia de una ley electoral injusta que favorece el bipartidismo y promueve con ello el empobrecimiento del debate político y la ausencia de otras alternativas (como decía una pancarta "ni cara $A$, ni cara $B$, queremos cambiar de disco"). Todo ello ha hecho que aumente el distanciamiento entre elegidos y electores, entre elites políticas y ciudadanos, lo que ha contribuido a que aumente la desafección hacia la políitica por parte de la ciudadanía. Y más aún ante la percepción de corrupción generalizada y de agotamiento de las viejas formas de representación y participación política y de sus principales actores - partidos y sindicatos-, como señalaban lemas como "No hay pan para tanto chorizo" o "No falta el dinero. Sobran ladrones".

Existe, finalmente, otro elemento relevante en este contexto como es el naufragio de la socialdemocracia (y de la izquierda, en general), así como sus principales instituciones, partidos y sindicatos. Los sectores políticos que supuestamente deberían haber evitado este proceso de polarización han sido percibidos crecientemente como

\footnotetext{
${ }^{15}$ Citado en el blog de Amador Fernández SAVATER, en: http://blogs.publico.es/fueradelugar/85/ la-cultura-de-la-transicion-es-una-cultura-tutelada-y-que-tutela
} 
incapaces e incluso como cómplices de esta deriva. Ante todos estos elementos, el movimiento se presenta como el inicio de un cambio ante una situación en la que se interpreta que el contrato social que garantizaba la paz social a cambio de la adquisición y mantenimiento de los derechos sociales ha sido roto por los recortes y la amenaza del desmantelamiento del estado de bienestar. Como apuntaba uno de los carteles de Juventud Sin Futuro "Nos habéis quitado demasiado, ahora lo queremos todo".

\subsection{La "narrativa de la indignación" como elemento catalizador del malestar}

Existe un elemento catalizador de todos estos agravios. El último año ha dado a luz a un sinfín de libros, panfletos y artículos orientados todos en una misma dirección: denunciar las causas de la crisis y su injusta salida y llamar a la movilización social y ciudadana. No sólo cabe tener en cuenta el "Indignez-vous!" de Stephan HESSEL, que se ha convertido en la punta de lanza de todo este mensaje a escala española, pero también europea, sino a otros muchos como: el "Manifiesto de los Economistas aterrados"; "Delito de silencio" de Federico MaYor Zaragoza; "Caída libre" de Joseph Stigutz; el best-seller "Algo va mal" del fallecido historiador socialdemócrata Tony JUDT; el libro coral "Reacciona", o bien el oscarizado documental "Inside Job", que ha dado la vuelta al mundo, denunciando la conquista que Wall Street ha logrado de la Casa Blanca en las últimas tres décadas ${ }^{17}$.Finalmente, a estas obras se puede añadir en clave local e irónica el cortometraje Españistán de Aleix SALó que de forma amena explicaba la crisis del modelo productivo español española e hizo furor en Internet con 2,5 millones de visitas en 8 días ${ }^{18}$.

Todos estos relatos, muchos de los cuales han sido curiosamente abanderados por figuras de edad muy avanzada y que se han convertido en referentes éticos (Hessel, pero también en España, José Luis Sampedro), han ido confluyendo en una "metanarrativa de la indignación", fundamentada en cuestiones que hasta el momento no habían sido abordadas con tal sentido de urgencia: la pérdida de

\footnotetext{
${ }^{16}$ Todas estas obras no están citadas en la bibliografía ya que no se han utilizado propiamente para el contenido del artículo.

17 "Españistán", por Aleix SALó, en: http://www.youtube.com/watch?v=N7P2ExRF3GQ. El economista Arcadi OLIVERES también logró una considerable atención, entre otras cosas, mediante el vídeo "El origen de las migraciones", que también recibió varios millones de visitas durante esos meses: http://www. youtube.com/watch? $v=V l e l J a 79 J u o$
} 
soberanía y la consolidación de una suerte de "mercadocracia"19, el incremento de las desigualdades sociales en los países del norte, la supeditación de la política a los poderes financieros y las grandes corporaciones mediáticas, y un largo etcétera. La construcción de este relato ha sido crucial en el actual proceso, convirtiéndose en un catalizador de percepciones y frustraciones sociales que llevaban tiempo acumulándose.

\subsection{Experiencias previas que contribuyeron al surgimiento del movimiento}

Con este contexto de fondo (polarización social y desafección política) y este poderoso elemento catalizador (jindignaos!) queda saber cómo empezó todo y quién y cuándo activó el mecanismo de esta "tormenta perfecta". El 15-M no fue un movimiento repentino, sino el resultado de un proceso de experiencias y movilizaciones previas. Sin duda, el poder organizativo y articulador mediante internety las redes sociales ha sido el factor fundamental. Desde una perspectiva genealógica, la batalla contra la "Ley Sinde" (relativa a la regulación de webs y la protección de la propiedad intelectual) debe considerarse como un punto de referencia esencial. Desde finales de 2009 hasta febrero de 2011, la red albergó una movilización sin precedentes en la que se criticaba la medida por considerarla como un instrumento que atentaba contra la neutralidad en la red. Todas las acciones desde entonces confluyeron para tratar que los grupos parlamentarios votaran en contra de dicha medida. La ley fue finalmente aprobada por el Congreso en febrero de 2011 (gracias a la posición favorable de PP, PSOE y CiU), pero acabó suscitando toda una serie de reacciones centradas en la crítica a dichos partidos: en febrero de 2011 , nacerá Nolesvotes.com, iniciativa que instaba a no votar a los grupos que habían respaldado la Ley Sinde y que criticaba duramente la corrupción política - la ley electoral, por considerarla injusta y poco representativa; y un mes antes, en enero de 2011, también logró un importante eco Anonymous, por sus ataques coordinados a las webs del Congreso y Senado y de los principales partidos.

En paralelo a esta denuncia contra el recorte de derechos en la red, fueron también articulándose desde internet un buen número de iniciativas que confluían en expresar su indignación ante la situación social, política, económica y financiera, las más importantes fueron: en octubre de 2010, ADESORG ${ }^{20}$; en diciembre de

\footnotetext{
18 Josep RAMONEDA, "¿Democracia o mercadocracia?, El País, 11 de mayo de 2010, en: http://www. elpais.com/articulo/cataluna/Democracia/mercadocracia/elpepiespcat/2010051 lelpcat $4 /$ Tes

${ }^{19}$ Asociación Nacional de Desempleados, en: hitp://adesorg2009.magix.net/website
} 
2010, Juventud Sin Futuro ${ }^{21}$; en enero de 2011, "Ponte en Pie"22; y en febrero de 2011 , "Estado del Malestar"23. Los meses anteriores también habían presenciado una proliferación de colectivos en defensa de la sanidad pública, reclamando una fiscalidad más progresiva, reivindicando la abolición de los paraísos fiscales y la aprobación urgente de un Impuesto a las Transacciones Financieras (ITF) o respaldando a las decenas de miles de personas que estaban siendo desahuciadas por los grandes bancos.

Uno de los hitos importantes se producirá en marzo de 2011, con la constitución del colectivo "Democracia Real Ya" (DRY). De manera coordinada con muchos de estos colectivos y plataformas que habían surgido en los últimos meses, DRY convocará una gran manifestación para el 15 de mayo de 2011, a la cual fueron sumándose paulatinamente numerosas ciudades españolas ${ }^{24}$. En su manifiesto fundacional, DRY plasmará, como hemos visto anteriormente, muchos de los agravios que habían ido manifestándose de manera puntual en las diferentes iniciativas, subrayando su carácter apartidista y evidenciando un fuerte componente de demanda de regeneración social y ética ${ }^{25}$. Desde inicios de marzo de 2011 hasta el 15 de mayo, la organización en la red adquirirá, como lo hiciera con la Ley Sinde, un carácter extraordinario: blogs, grupos en Facebook, listas de correos, vídeos youtube y, sobre todo, la intensificación de Twitter como canal de articulación y movilización.

Todas estas movilizaciones, además, cabe enmarcarlas en un proceso de acción colectiva que hunde sus raíces en el movimiento altermundialista iniciado en los noventa con el alzamiento zapatista (1994) o las protestas en Seattle contra la OMC (1999). También han sido importantes las movilizaciones contra la guerra de Irak (2003), las del 13M (2004) contra el Gobierno de José María Aznar por su gestión e información de los atentados de Madrid de ese mismo año (y que movilizó a miles de personas mediante el envío masivo de 'sms'), las manifestaciones del movimiento

\footnotetext{
20 Juventud Sin Futuro, en: http://www.juventudenaccion.info

${ }^{21}$ Ponte en Pie, en: http://ponteenpie.blogspot.com/

${ }^{22}$ Estado del malestar, en: http://malestar.org/
}

\begin{abstract}
${ }^{23}$ Asimismo, también habían ido proliferando iniciativas ciudadanas que denunciaban algunos de los asuntos que posteriormente el movimiento 15-m incorporará a su agenda: http://www.publico.es/ dinero/372684/aluvion-de-iniciativas-sociales
\end{abstract}

${ }^{24}$ Democracia Real Ya, en: http://www.democraciarealya.es/manifiesto-comun/ 
"V de Vivienda" (2006-2008) e incluso la celebración de los diferentes Foros Sociales Mundiales y Europeos. En un sentido más global, las revueltas en el mundo árabe y las protestas en Islandia o Grecia también han contribuido, de algún modo, a configurar este imaginario colectivo y un estado de ánimo determinado que derivó finalmente en el 15-M. Asimismo, las referencias históricas ("68, apartaos, que nosotros vamos en serio") también han tenido una cierta presencia.

\section{Novedades en las formas de acción colectiva introducidas por el I5-M}

Como hemos visto hasta ahora, el movimiento 15-M presenta algunas características que lo convierten en un fenómeno verdaderamente particular por su desarrollo, el contexto en el que emerge, y la genealogía que explica su aparición no tan repentina como a veces se ha planteado. El siguiente apartado pretende profundizar en el análisis de aquellos elementos novedosos que desde el punto de vista de la acción colectiva se dan en el $15 \mathrm{M}$.

Dentro de los estudios sobre la acción colectiva, en los últimos años se ha destacado el papel que juega la cultura en los procesos de movilización social (CRUZ MARTINEZ, 1997). Así, influenciados por los planteamientos de antropólogos como GeERTZ (1990), diferentes teóricos han visto en la cultura una especie de "caja de herramientas" compuesta por símbolos, rituales, historias, y visiones del mundo, mediante la cual los actores construyen estrategias de acción. En esta línea, algunos trabajos han enfatizado el papel de la cultura como elemento que permite a los actores construir una estrategia de acción significando elementos culturales y dotándolos de significados particulares en el marco de la acción colectiva (CHHU AMPARÁN, 1999).

Dentro de este planteamiento general en el que se subrayan los aspectos simbólicos y culturales en la construcción de la acción colectiva, hay dos conceptos teóricos que queremos resaltar por su importancia. El primero es el concepto de "marco" planteado por SNOW Y BENFORD (1988). Por marco se entiende un esquema interpretativo que simplifica y condensa el mundo codificando selectivamente sujetos, situaciones, acontecimientos, experiencias y secuencias de acciones. De este modo, los marcos para la acción colectiva actúan como dispositivos que permiten pensar sobre el mundo, realizar un diagnóstico de la situación y llamar la atención sobre aquellas situaciones sociales que son definidas como injustas con el fin de llamar a la movilización social. 
El otro concepto es el de "repertorio" de acción colectiva que, tras ser planteado por TARROW (1997), puede ser definido como un conjunto limitado de rutinas aprendidas, conocidas, compartidas, aceptadas y llevadas a cabo mediante un proceso de selección relativamente deliberado. Con el uso de esta noción, se plantea que existe todo un abanico de formas familiares de acción conocidas tanto por los activistas como por sus oponentes (manifestaciones, huelgas, recogidas de firmas, etc.) y que pueden ser vistas como productos culturales que evolucionan lentamente ${ }^{26}$.

Partiendo de este planteamiento general cabe preguntarse qué novedades ha introducido el movimiento 15-M dentro de las formas de acción colectiva, pudiéndose observar al menos cinco grandes novedades: una renovación en las formas de movilización; una ruptura con las formas tradicionales de organización; ciertas innovaciones en el lenguaje empleado y en el modo en que se construye; la aparición de una identidad colectiva en torno al movimiento y la existencia de nuevas formas de deliberación y en las que internet y el espacio de las redes sociales es crucial y transversal a todo los elementos anteriores.

\section{I. Nuevas formas de movilización: el significado de las acampadas}

Como se ha señalado, existe un hilo de continuidad entre el movimiento 15-M y algunas movilizaciones previas vinculadas a los movimientos alterglobalizadores, a la vez que hay puntos en común con otras movilizaciones más locales como los movimientos Antibolonia, las movilizaciones protagonizadas por " $\mathrm{V}$ de Vivienda" o las más recientes de "Juventud sin futuro". En este hilo de continuidad, tal y como señala IGLESIAS (2005), también existe un proceso de aprendizaje e incorporación al repertorio de la acción colectiva de nuevas formas de expresión de la protesta.

Sin embargo, la acampada como acción que se incorpora al repertorio de la contestación de una forma exitosa es una expresión de la protesta "relativamente" nueva, más allá de su uso en algunas movilizaciones en el conflicto laboral de Sintel, en las más alejadas acampadas por el 0,7 o en las acampadas contra la guerra en Barcelona en el año 2003. La decisión de acampar -en una decisión tomada en una mezcla de audacia, ingenuidad, improvisación y creatividad-es la que hará que una manifestación exitosa por su capacidad de movilización tome un giro inesperado y en el caso del movimiento $15-M$ presenta algunas peculiaridades propias.

${ }^{25}$ Un estudio en profundidad de la evolución de los diferentes repertorios de acción colectiva, así como una clasificación de éstas entre el repertorio tradicional y el repertorio moderno puede verse en TILYY (1978). 
Según CoRsín y Estalella (2011) existe una continuidad, en cuanto a los aprendizajes previos de algunos participantes y en los procesos de innovación política, entre el 15-M y algunas experiencias de autogestión desarrolladas en los meses previos en Madrid como en el proyecto social de La Tabacalera o en el centro social ocupado del Patio Maravillas. Estos proyectos, basados en la autogestión y en el asamblearismo, serán en buena medida referentes de los que beberá la experiencia iniciada en Sol con la salvedad de que en este caso se realizarán en el espacio público. Asimismo, en las raíces de la protesta no faltan referentes y paralelismos con el contexto internacional como las revoluciones del mundo árabe ${ }^{27}$. No obstante, cabe considerar que en el caso del 15-M el sentido que se le da a la acampada adquiere otros significados, generándose una identidad enraizada en las características de los contextos estatal y local.

Tras el primer desalojo de la acampada, millares de ciudadanos se acercan a la plaza a expresar su solidaridad, la repulsa por la represión ejercida y a seguir el ejemplo de los primeros acampados. Parafraseando el lema de Obama -"Yes, we camp"-al retomar de nuevo la acampada se reafirman en una decisión que es tomada como ejemplo en numerosas localidades en lo que se convierte en un gesto de desobediencia civil.

Además, el hecho de que la acampada sea realizada en la principal plaza pública de una ciudad está revestido de un fuerte simbolismo. La plaza pasa de ser un espacio físico sin más, o incluso un lugar de paso, a convertirse en el espacio de encuentro por excelencia. Con ello, se inicia un proceso de reapropiación y resignificación del espacio público cuya máxima expresión es el cambio de nombres de algunas plazas donde se desarrollan las acampadas como "Plaza 15 de Mayo".

De este modo, la plaza pasa a convertirse en un símbolo que inicia un proceso de traslación del espacio: la calle deja de ser un lugar de paso y la ciudad abandona su papel de ciudad-escaparate pensada y creada para el ciudadano como consumidor, para emerger la "ciudad vivida" y la plaza como punto de referencia y encuentro con el vecino, y como ágora abierta a todos los ciudadanos. Más importante todavía, tal y como señalaba Amador Fernández SAVATER ${ }^{28}$, con las

\footnotetext{
${ }^{26}$ Como en algunos carteles que hablaban de la "Plaza Tahrir" de Madrid en recuerdo a la plaza de este nombre de El Cairo y emblema de la resistencia frente a la dictadura de Mubarak.

${ }^{27}$ Ver las diversas entradas sobre Apuntes de Acampada Sol en blog: http://acuarelalibros.blogspot. com/
} 
movilizaciones no se trata tanto de "tomar la calle", sino de "crear la plaza". Así, dentro de esta lógica, no es extraño que la ocupación de la plaza sea presentada como un espacio privilegiado para la participación democrática en la que la acampada se organiza a través del trabajo asambleario y la existencia de diversas comisiones y donde, más allá de su funcionalidad, la acampada se convierte en un espacio de innovación política.

La plaza esconde una dimensión más: es un espacio de construcción desde la "heterotopía". FERNÁNDEZ SAVATER acude a este sugerente término para diferenciarlo de la utopía: mientras la utopía es otro mundo, la heterotopía es una pequeña distancia con respecto a la realidad que nos permite habitarla y pensarla de otra manera ${ }^{29}$. Las plazas trataron de jugar ese papel, el de tomar distancia sin separarse de la realidad reapropiándose de los espacios y redefiniendo el lenguaje y las relaciones sociales. Un espacio en el que no se busca la separación de la realidad sino avanzar en la construcción de un espacio inclusivo donde quepan much@s en él. Generar un espacio desde el cual pensar a través de la inteligencia colectiva una sociedad radicalmente diferente como expresaban los lemas "Plaza (Sol)ución" o "la clave está en Sol".

Con ello, la plaza pasa a convertirse en un emblema y un símbolo poderoso para el movimiento, o utilizando la terminología introducida con anterioridad, en un marco para la acción colectiva que ayuda a codificar e interpretar la realidad.

\subsection{Nuevas formas de organización: el ADN de las acampadas}

Un aspecto significativo ha sido el tipo de organización resultante en cada una de las acampadas. Las acampadas han significado una ruptura frontal con las formas de organización más habituales (partidos, sindicatos, etc.) y han destacado por la aceptación y la conexión social que han suscitado. Existen varios elementos que definen a estos espacios: un carácter descentralizado, desde un principio una mayoría apostó por continuar los debates y asambleas en los diferentes barrios de cada una de las ciudades; transparente, todo el que ha querido ha podido acceder a los debates, a sus actas y a las decisiones que se iban adoptando; autogestionado, ha imperado la lógica del "hazlo tú mismo", a la hora de convocar o de organizar asambleas y movilizaciones; horizontal, ya que se han evitado estructuras jerárquicas, que reproduzcan determinados tics institucionales, y autorepresentativo, rechazando la utilización de etiquetas identificativas o la visibilización de líderes

28 "Apuntes de acampada sol", en: hitp://blogs.publico.es/fueradelugar/files/2011/07/cahiers.pdf 
concretos, hecho que ha desconcertado enormemente a los medios de comunicación y a las instituciones que iban en busca de interlocutores.

Asimismo, las acampadas se han caracterizado por ser un espacio abierto e inclusivo, en el que todo el que ha querido ha podido participar de las diferentes comisiones, grupos de debate y asambleas que se han ido constituyendo y que han ido abordando las principales problemáticas. El perfil de los participantes ha sido también ideológicamente plural y diverso. Se destacó desde un principio su carácter apartidista y la participación de personas que podían considerarse tanto de derechas, de centro como de izquierdas, si bien la mayoría convienen que muchas de las propuestas tienen un sesgo claramente socialdemócrata y de izquierdas. En este sentido, en las plazas han confluido desde personas que han tenido su primera experiencia de militancia política hasta individuos ya organizados en el marco de otros espacios ${ }^{30}$, si bien en las acampadas no han existido etiquetas ni pertenencias identificables. La presencia intergeneracional ha sido otro elemento distintivo, ya que no sólo ha sido la "revolución de los jóvenes", sino de gente de todas las edades que tenían en común la indignación, la desafección con las instituciones o una situación social extrema.

Finalmente, un elemento fundamental es la "no-violencia" como criterio, tanto "hacia dentro" (evitando que grupúsculos determinados sean capaces de boicotear determinadas acciones o protestas) como "hacia fuera" (ante la carga policial en Barcelona los llamamientos a la no-violencia fueron constantes, prevaleciendo a pesar de la contundencia de la actuación policial).

\subsection{Novedades discursivas y de lenguaje}

Otra novedad significativa del movimiento 15-M está en el discurso utilizado. El lenguaje inocente e incluso naíf utilizado en algunos comunicados por el $15-M$ se caracteriza por rehuir la confrontación y apelar, en la gran mayoría de los casos, al carácter inclusivo y transversal del movimiento con un discurso con un marcado tono ciudadanista.

Estos elementos, unidos a la sorpresa que causó la emergencia del movimiento, la horizontalidad en las decisiones, la rotación establecida en la portavocía, y la

\footnotetext{
${ }^{29}$ Por ejemplo, existían individuos pertenecientes a espacios de izquierda alternativa y minoritaria o bien a espacios más libertarios o personas procedentes de la izquierda institucional o del tejido asociativo tradicional (asociaciones de vecinos, ONG, etc.), entre otros perfiles.
} 
audacia con la que el 15-M supo moverse en los primeros momentos en la arena política para evitar todo etiquetamiento fueron los que llevaron a este movimiento a conseguir introducir su mensaje en la agenda política. Estas mismas características fueron las que dificultaron a los medios de comunicación la identificación del movimiento: saber quiénes eran, qué ideología tenían, quién estaba "detrás" de ellos o ver si era un fenómeno cuyo fin era condicionar la campaña electoral en marcha. Si bien en gran parte de los medios se presentó en los inicios a sus componentes como "apolíticos", "antisistema", "perroflautas" o "violentos", entre otros adjetivos, en un intento de deslegitimarlos y estereotiparlos, al final fue el término de "indignados" el que acabo imponiéndose.

Asimismo, en el movimiento no han faltado los mensajes llenos de ironía y creatividad sobre cómo eran vistos por la opinión pública. Es el caso de lemas como "no somos antisistema, el sistema es anti-nosotros", el dirigido al carácter supuestamente apolítico del movimiento -" ¿Apolíticos? ¡Superpolíticos!"-, o los mensajes dirigido a los políticos tras la supuesta ilegalidad de las masivas concentraciones realizadas el día de la jornada de reflexión: "Nos falláis y encima nos acalláis" o "Yo ya he reflexionado. Ahora que reflexionen ellos". En la misma línea de redefinir algunos términos, encontramos lemas que invitan a reflexionar sobre cómo se construye la realidad y cómo se construye el sentido común en torno a ésta ${ }^{31}$.

Pero más allá de estos mensajes en torno al modo en que el movimiento era presentado en la opinión pública, llaman la atención otras novedades discursivas que el movimiento trata de hacer y que de alguna manera construyen nuevos marcos de referencia a través de los cuales se reinterpreta la realidad.

Tal y como señala Martínez Roldán (201 1), es sumamente significativa la utilización que el movimiento hace del lenguaje frecuente de las redes sociales en un nuevo contexto como es el espacio urbano. Así sucede en expresiones como "Error en el sistema. Democracia not foud", o con el uso frecuente del símbolo "\#" utilizado en los hashtag. Esto muestra cómo el lenguaje de las TIC puede trascender este entorno adoptando un papel performativo.

Por otro lado, y más allá de esta cuestión, es significativa la toma de distancia en el lenguaje utilizado respecto a categorías fuertemente arraigadas y connotadas como "izquierda" $y$ "derecha", por considerarse que estos términos han sido va-

\footnotetext{
${ }^{30}$ Así sucedió con el debate en torno al uso de la violencia y quién está en condiciones de imponer su definición sobre la violencia como se expresa en lemas como "violencia es no llegar a fin de mes" o "violencia es cobrar 600 euros".
} 
ciados de contenido en las formas concretas de ejercer la política (en este sentido, se llega a firmar que "esta no es una cuestión de izquierdas contra derechas, sino de los de abajo contra los de arriba"). De este modo, el movimiento ha optado por trascender y desbordar esta división en sus discursos y hablar de arriba-abajo o incluso del derecho a la ciudadanía como un punto de encuentro amplio e inclusivo y como bandera de reivindicación.

En la misma línea, el movimiento interpela a la ciudadanía a través de un lenguaje con una identificación política débil, y con un lenguaje marcadamente ciudadanista en el que la defensa y reivindicación de los derechos sociales ocupa un lugar central. A través del lenguaje utilizado (identificación política débil, cierta ambigüedad en los términos utilizados, uso del femenino, uso de ciertos juegos de palabras como sucede con "(R)evolución"), se percibe un intento de querer construir en el marco del movimiento un nosotr@s amplio que promueva un cambio gradual hacia un nuevo estado de cosas.

\subsection{La construcción de una identidad compartida}

Desde hace algunos años, diversos teóricos han venido destacando el papel fundamental que tiene la construcción de una identidad compartida en la acción colectiva. Para Melucal (1999), en línea con las propuestas constructivistas, los movimientos sociales confieren a los sujetos participantes una identidad que a su vez permite construir modos alternativos de asumir la vida. Partiendo de esta idea general de los movimientos sociales como generadores de identidades colectivas, cabe preguntarse qué tipo de identidad compartida promueve el movimiento 15-M.

A diferencia de otros movimientos sociales donde se parte de identidades colectivas más definidas (como sucede por ejemplo en las llamadas a la movilización de la clase obrera), en el 15-M se percibe un esfuerzo por huir de aquellos símbolos identitarios fuertemente connotados desde el punto de vista simbólico (banderas, emblemas, etc.). En su lugar, como ya se ha señalado, el movimiento trata de construir un sujeto colectivo abierto e inclusivo.

Con ello, el movimiento trata de despojarse de toda simbología propia más allá del lugar que ocupa la plaza como espacio emblemático por ser un ágora abierto a todos los ciudadanos. Algo similar ha sucedido en algunas movilizaciones realizadas como la manifestación del 19-J donde apenas había símbolos de carácter político, frente a otras movilizaciones anteriores donde abundaba la simbología de carácter ideológico o de alguna organización política o sindical. 
Finalmente, el uso de este lenguaje que rehúye en muchas ocasiones del posicionamiento dentro del eje derecha-izquierda ha generado en ocasiones recelos entre algunos sectores más ideologizados y entre militantes que no compartían esta cuestión. Así mismo, la invitación a no usar símbolos connotados y otras cuestiones como la supuesta capacidad de autoconvocatoria han hecho que desde algunos sectores se vea en el 15-M una especie de "revolución naranja" similar a la vivida en las antiguas repúblicas soviéticas que permita canalizar la disidencia aunque con una escasa capacidad para promover cambios efectivos ${ }^{32}$. Finalmente, esta ausencia de auto-identificación ha favorecido los intentos por parte de algunas organizaciones de querer instrumentalizar el movimiento o que se hayan achacado a los "indignados" algunas acciones que no han sido promovidas directamente por éstos.

\subsection{Nuevas formas de deliberación: la wiki-agenda e internet como motor del movimiento}

Un último elemento característico es la agenda que el 15-M ha ido construyendo. La novedad reside no tanto en sus demandas concretas sino en la forma en que dicha agenda se ha ido configurando. Como hemos señalado anteriormente, buena parte de esta agenda ya había sido planteada por algunos partidos políticos (la mayoría de los cuales no se han atrevido a defenderla a pesar de incorporarla en sus programas) y por diferentes movimientos sociales. Para Manuel CASTELLS (2011), sin embargo, la agenda política del $15-\mathrm{M}$ se caracteriza por "buscar una salida de la crisis hacia un modo de vida construido colectivamente", en el que todo el mundo puede hacer aportaciones y en el que los consensos, muchos de los cuales responden a demandas tradicionales, son generados y construidos nuevamente desde abajo, como si fueran un documento "wiki", abierto a la participación, opinión, sabiduría y subjetividad de cada uno de sus participantes. Como algunos han dicho, las acampadas y el movimiento 15-M se han convertido en una escuela de aprendizaje político para los que acaban de llegar pero también para los que llevan tiempo en esto. Un aprendizaje que es un "aprender haciendo" en el que confluyen nuevas y viejas maneras de hacer, de entender la política y la sociedad, o de convocar y organizarse ${ }^{33}$.

\footnotetext{
${ }^{31}$ Algunos comentarios que van en esta dirección pueden encontrarse, por ejemplo, en: hitp://maratasaltarloscielos.blogspot.com/2011/06/el-indignado-punset-los-discursos.html

32 "Maig del Srixanta-tuit", por @galapita y @hibai, en: http://enfocant.net/noticia/ maig-del-seixanta-tweet
} 
Un elemento fundamental para entender el origen y el futuro del movimiento 15-M es su dimensión virtual. En este trabajo colectivo ya no sólo importa la presencia física como tradicionalmente ni tampoco los indicadores habituales para medir el éxito o fracaso de una convocatoria determinada (número de manifestantes, etc.). Las calles y las plazas han sido un lugar importante de visualización y reivindicación, pero la red ha sido clave en la articulación y como espacio de participación política, desde el cual incluso miles de personas han seguido por streaming las asambleas que tenían lugar en las plazas. Todo esto ha demostrado que la intensidad del intercambio y la comunicación presencial no tienen por qué ir en detrimento de la digital y viceversa. El binomio calle-red, la tensión analógico-digital, ha derivado no en algo dicotómico sino complementario.

Así las cosas, internet se presenta como el espacio de discusión y articulación política clave para las transformaciones sociales y políticas que están teniendo lugar. Pero su centralidad también reside en la ruptura, seguramente irreversible, de un doble monopolio: el de la forma de hacer política, a través de los partidos políticos y de las instituciones; y el de la forma de comunicar, mediante los medios de comunicación de masa. La trascendencia de ambos factores es tal que hacen pensar que verdaderamente son lo que explica que podamos encontrarnos ante un cambio de época, un punto de inflexión histórico.

Sobre el factor político, Antoni GutiérRez RuBí (2011) considera que, en efecto, el 15-M ha demostrado que puede "hacerse política sin partidos", modificando substancialmente la noción de poder. Ahora, la red da poder a quien tiene ideas, no a quien es fuerte o tiene una organización o muchos recursos. Internet ha cambiado así las reglas de juego, la liga y hasta el árbitro, evidenciando la existencia de una plataforma múltiple y global en la que todos decidiremos lo que es importante y lo que no lo es. Para GutiérRez Rubí, esta nueva manera de comunicarnos, de organizarnos y de construir valor afecta a todo tipo de instituciones: las que lo entiendan pronto y rápido comprenderán el cambio y serán capaces de adaptarse a él; las que no lo entiendan, quedarán al margen ${ }^{34}$.

\footnotetext{
${ }^{33}$ Prueba de toda esta dinámica y de su impacto son las reacciones que muchos partidos tuvieron en las siguientes semanas. Algunos puntos de la agenda del 15-M fueron abanderados por los principales partidos políiticos, de derechas e izquierdas, e incluso han sido ya motivo de debates parlamentarios (dación en pago, reforma de la ley electoral, canon digital, ...). Al menos en esta primera etapa, los partidos parecen ser conscientes de la legitimidad social que el $15-M$ ha acaparado y de la importancia de establecer sutilmente algunos gestos de complicidad. Algo diferente es la capacidad que los partidos e instituciones tradicionales tendrán para incorporar el funcionamiento en red a su modus operandi sin que parezca artificial o forzado.
} 
Por otra parte, tanto el proceso de la Ley Sinde como el 15-M (como experiencias recientes en Twitter con la protesta ante la decisión en el Consejo de RTVE) han puesto de manifiesto la fractura del monopolio mediático. Para sectores cada vez más importantes de la sociedad, los principales periódicos, televisiones y radios ya no son su principal fuente de información. El impacto de herramientas como Facebook y Twitter ha sido esencial en todo este proceso (aquí y en las revueltas árabes), no solo como mecanismo de articulación y debate, sino también como espacio en el que se contrastan informaciones y se acelera su intercambio ${ }^{35}$. La pérdida de esta centralidad comunicativa y la diversificación de canales de información será absolutamente clave en el futuro del movimiento y de la nueva época que se presenta. La década del "está pasando, te lo estamos contando", ha dado paso al mundo del "está pasando, lo estamos haciendo y te lo estamos contando, sin intermediarios, en tiempo real y al mundo global" ${ }^{\prime 36}$.

\section{Conclusiones y aspectos a tener en cuenta}

Existe cierto consenso a la hora de considerar que el $15-M$ ha venido para quedarse. Más que estar ante una protesta coyuntural en un contexto de crisis sistémica, nos encontramos seguramente ante una expresión social de tipo estructural que integra elementos políticos, sociales, económicos, culturales y éticos. Más allá de la continuidad en las plazas o asambleas de barrio o en su capacidad para convocar a más o menos personas a una manifestación, como hemos visto, el 15- $M$ cuenta con un potencial extraordinario: nuevas formas de organización y movilización, de expresión y de lenguaje y nuevos canales que rompen con los habituales. Asimismo, su carácter difuso o las rápidas transformaciones sociales que se están produciendo en el contexto actual hacen muy impredecible su futuro. A modo telegráfico señalamos algunos elementos que consideramos que hay que tener en cuenta para intuir el posible horizonte de este movimiento:

\footnotetext{
${ }^{34}$ Durante las cargas policiales del 27M en Barcelona, en pocos minutos la red se llenó de vídeos que mostraban la brutalidad de la actuación policial, dejando sin argumentos a los representantes del Gobierno de Catalunya, los cuales quedaron en evidencia. Por otra parte, los intentos a veces de desvirtuar o desfigurar decisiones o discusiones que tenían lugar en las acampadas por parte de algunos medios, quedaban rápidamente desacreditados tras el comunicado emitido a través de la página Facebook o de Twitter de las acampadas, los cuales contaban con decenas de miles de seguidores que reproducían de inmediato la información.
}

${ }^{35}$ En GUTIÉRREZ-RUBI: http://www.slideshare.net/Antoni/la-xarxa-nova-via-de-ressitncia 
a) Existe cierta rivalidad, confrontación e incluso desconfianza mutua entre las nuevas formas de acción colectiva y las más tradicionales (partidos políticos y sindicatos, principalmente). Un aspecto importante a tener en cuenta son aquellos actores sociales o políticos que logren sumar las experiencias y las sinergias de ambos lados. En este sentido, ATTAC $v$ otros colectivos nacidos en los últimos quince años pueden aportar ese potencial unificador entre estas dos formas de movilizar y expresarse, una enraizada claramente en la modernidad y la otra con una fisonomía mucho más posmoderna.

b) El 15-M está compuesto mayoritariamente por los sectores más críticos del precariado ${ }^{37}$, entre los que se cuentan sobre todo los jóvenes, que son los que más han sufrido las consecuencias de la precariedad y quienes padecerán más las consecuencias de algunas medidas ya tomadas como la reforma laboral o de las pensiones. Queda por ver si el movimiento es capaz de conectar y aglutinar a otros sectores hasta ahora poco representados en él como algunos sectores tradicionales de la clase trabajadora o, por ejemplo, una mayor presencia de población inmigrante.

c) Hasta el momento el movimiento ha conseguido obtener el apoyo de amplios sectores de la ciudadanía, tener una gran capacidad de movilización y, sobre todo, liberar una gran energía creativa. A su vez, ha mostrado una extraordinaria capacidad de metamorfosis en sus diferentes formas de acción colectiva: de la manifestación ("toma la calle"), a las acampadas ("toma la plaza") y de ahí a una progresiva descentralización en los diferentes barrios ("toma los barrios"). En este contexto, queda por ver si el movimiento es capaz de extenderse con éxito a otros espacios más allá del espacio público, como por ejemplo en los diferentes lugares de trabajo, o qué nuevas formas de acción colectiva eficaces pueden emerger en estos nuevos contextos.

d) El incipiente proceso de internacionalización del 15-M constituye uno de los principales retos del movimiento. Como se ha visto en los últimos meses, existe un diagnóstico similar y un malestar compartido en diferentes lugares (EEUU, Grecia, Italia, Israel, etc.) ante la situación social y económica, lo que ha hecho que el 15-M haya tenido réplicas análogas en diferentes países. Más allá de

36 El "precariado" es una expresión tomada del estudio de la Fundación Friederich Ebert (http:// www.fes.org.ar/), vinculada al partido socialdemócrata aleman SPD. Un neologismo, cuyo título en castellano puede traducirse como "la sociedad en transformación". Hace referencia a personas con contratos de trabajo temporales, o que pasan largas temporadas en el desempleo, con bajos salarios cuando trabajan, sin formación y sin redes familiares. 
sus variantes locales, queda por ver si es posible sostener en el tiempo formas de coordinación y una agenda común entre todas estas movilizaciones.

e) Finalmente, no es posible afirmar, de momento, si el 15-M está siendo capaz o no de influir verdaderamente en la agenda política o cambiar el rumbo del actual estado de cosas. Se necesita cierta distancia y perspectiva histórica -como se demuestra, por ejemplo, en el análisis de otros movimientos sociales históricos- para determinar este aspecto. Lo más importante es que el 15-M podría estar anticipando algunas de las reivindicaciones y algunas de las formas de organización social y política de los próximos años.

f) Para terminar, un último apunte para la reflexión. Con la aparición del movimiento $15-M$ y sus demandas de mayor profundización democrática cabe pensar si no estamos ante la aparición de una nueva narrativa metapolíitica que va a nutrir a los movimientos sociales en el futuro, entendiendo por metapolítica el relato que dibuja un horizonte ideal y que nutre y da sentido a las acciones concretas de gestión de lo público, que sería el terreno de la política.

Partiendo de esta afirmación, cabe plantearse como hipótesis si el movimiento $15-M$ no es una prueba más de que se está abriendo el inicio de un debate político de largo recorrido que tiene como ejes principales la necesidad de reinventar la democracia y la desmercantilización de algunos ámbitos de la sociedad y de la vida. Un debate donde se reivindique una democracia entendida de una forma amplia y que presente como eje central la recuperación de la soberanía popular, integrando dentro de esa perspectiva la denuncia al poder económico y de los mercados como elemento cercenador de esa democracia, y la necesidad de una mayor participación en la toma de decisiones que afecten a la colectividad.

Está por ver qué recorrido tiene una propuesta de este tipo en un contexto caracterizado por el avance del neoliberalismo, el sometimiento de los Estados a los poderes económicos, y la crisis de legitimidad que se ha producido en torno a la democracia representativa.

En suma, el artículo ha intentado ofrecer algunas pistas e intuiciones de un fenómeno incipiente $y$, sobre todo, socialmente muy complejo y dinámico. Asimismo, el análisis del movimiento 15-M cabe situarlo en un marco y en una coyuntura histórica de constantes transformaciones sociales, políticas y económicas, por lo que para entender la profundidad y los cambios que supone la emergencia del movimiento será necesario un análisis constante. 


\section{Bibliografía}

Castels, M. (2011), "Wikiacampadas", La Vanguardia, 28 de mayo de 2011, en: http://www.lavanguardia.com/opinion/articulos/20110528/54160922879/ wikiacampadas.html

ChiHu Amparan, A. (1999) "Estrategias simbólicas y marcos para la acción colectiva": Polis 99, Anuario de Sociología, pp. 41-65, México, UAM-Iztapalapa.

Corsin, A. y Estalella, A. (2011) "\#spanishrevolution": Anthropology Today, Vol. 27, No. 4, pp. 19-23.

CRUZ, R. (1997) "La cultura regresa al primer plano", en Pérez Ledesma, M. y CRUZ, R., Cultura y movilización en la España contemporánea, Madrid, Alianza Universidad, pp. 13-35.

GeERTZ, C. (1988) La interpretación de las culturas, Barcelona, Gedisa.

GutiérReZ-RuBí, A. (2011), "De la indignación al compromiso", Blog personal "Artículos y reflexiones", 6 de junio de 2011, en: http://www.gutierrez-rubi. es/2011/06/06/de-la-indignacion-al-compromiso/

IGLESIAS, P. (2005) "Un nuevo poder en las calles. Repertorios de acción colectiva del Movimiento global en Europa. De Seattle a Madrid": Política y sociedad, 2005, Vol. 42, núm. 2, 63-69.

Meluccl, A. (1999) Acción colectiva, vida cotidiana y democracia, México, El Colegio de México, Centro de Estudios Sociológicos.

SANTOS, B. DE S. (2005) Reinventar la democracia. Reinventar el Estado, Buenos Aires: CLACSO.

SNOW, D. A. y Benford, R. D. (1988). "Ideology, Frame Resonance, and Participant Mobilization": International Social Movement Research 1: 197-217.

TARROW, S. (1997) El poder en movimiento. Los movimientos sociales, la acción colectiva y la políitica, Madrid, Alianza.

TILY, C. (1978) From Mobilization to Revolution, New York, The University of Michigan Random House. 